\title{
GREEN SYNTHESIS OF SILVER NANOPARTICLES USING MEDICINAL PLANT ACALYPHA INDICA LEAF EXTRACTS AND ITS APPLICATION AS AN ANTIOXIDANT AND ANTIMICROBIAL AGENT AGAINST FOODBORNE PATHOGENS
}

\author{
SOUMYA MENON, HAPPY AGARWAL, S. RAJESH KUMAR, S. VENKAT KUMAR*
}

School of Bio-Sciences and Technology, VIT University, Vellore 632014, TN, India

Email: venkatkumars@vit.ac.in

Received: 28 Apr 2017, Revised and Accepted: 22 Aug 2017

\begin{abstract}
Objective: In the present study, silver (Ag) nanoparticles was synthesized by traditionally used medicinal plant Acalypha indica, which was characterized using various advanced tools, and its antioxidant as well as antimicrobial properties, was studied against food pathogens.

Methods: The synthesis of silver (Ag) nanoparticles from the leaf extracts were monitored with the characterization of silver nanoparticles with the help of UV-visible spectrophotometer. The optimized time for the synthesis of nanoparticles was $3 \mathrm{~h}$, followed by fourier transform infrared spectroscopy (FT-IR), X-ray diffraction (XRD), surface emission microscopy analysis (SEM), transmission electron microscopy (TEM), atomic force microscopy (AFM) and energy dispersive spectroscopy analysis (EDX). The antioxidant activity was evaluated by using 2,2-diphenyl-1-picrylhydrazyl (DPPH) and reducing power assay, while antifungal activity was performed against food pathogens by measuring the zone of inhibition values (ZOI).

Results: The Ag nanoparticle produced, have an average particle size of $34 \mathrm{~nm}$ with a spherical shape, analyzed from the XRD studies, and size was confirmed with the SEM and TEM analysis. The FTIR analysis gave information about the possible compounds adsorbed on the surface of the Ag nanoparticles. The Ag nanoparticles had good reducing power than the standard and the $\mathrm{IC}_{50}$ value for $\mathrm{Ag}$ nanoparticles was $5 \mathrm{mg} / \mathrm{ml}$, while the standard taken had an IC 50 value of nearly $6-7 \mathrm{mg} / \mathrm{ml}$. The fungal strain A. fumigates showed ZOI of $133 \%$ at $75 \mu \mathrm{l}$ of concentration proving that Ag nanoparticles can act effectively against this strain when compared to other strains even at low concentrations.
\end{abstract}

Conclusion: The produced Ag nanoparticles can be used for its therapeutic purposes and for large-scale synthesis in food industries for food preservation or packaging.

Keywords: Green synthesis, Silver nanoparticles, DPPH activity, Reducing power, Antifungal, and food preservation

(C) 2017 The Authors. Published by Innovare Academic Sciences Pvt Ltd. This is an open-access article under the CC BY license (http://creativecommons.org/licenses/by/4.0/) DOI: http://dx.doi.org/10.22159/ijap.2017v9i5.19464

\section{INTRODUCTION}

Nanoparticles can be synthesized from different approaches which includes chemical, biological and the physical methods like the photochemical and chemical reductions which are being used in reverse micelles, reduction by various solutions, radiation assisted, thermal decomposition, microwave heating, electrochemical sonication and so on. The biological methods are now widely being used because in case of chemical methods, the chemicals used can be highly toxic and the products are not friendly to the environment. The demand of using an eco-friendly method for the nanoparticle synthesis has led to a new approach "green nanotechnology" which is accomplished without the use of toxic chemicals. The plant or microbial mediated methods are widely being followed as they are simple, cost effective, eco-friendly and give rapid results. As, plants are rich in various proteins and secondary metabolites including quinones, flavonoids, saponins, and terpenoids, which are involved in the stabilization or reduction of the nanoparticles [1-4].

The nanoparticles can be reduced using the various parts of plants, which includes black tea leaf extract [5], citrus fruits (Citrus limon, Citrus reticulata, Citrus sinensis) aqueous extract [6], seeds like Mucuna pruriens [7] and also flowers like Nyctanthes arbortristis [8].

The silver nanoparticles are the most concentrated interest for research due to its potential in applications like to transform the physical, electronic and optical properties of a compound, treatment of cancer, as medical devices, antimicrobial coatings of paint, textiles, also biological or chemical sensing, also possess antiinflammatory, antiviral, antifungal and antiplatelet activities $[9,10]$.

In this present study, a plant extract of Acalypha indica are used, which grows in wastelands, gardens, and roadside. They are herbaceous annual weed that grows up to a height of $15 \mathrm{~m}$ [11]. It falls under the family of Euphorbiaceae, which has diuretic, antimicrobial, anti-helminthic properties and used in the treatment of respiratory problems like bronchitis, pneumonia, and asthma [12]. In the study, the silver nanoparticles were synthesized from these plant extracts, characterized and checked for their antioxidant and antifungal activity against food pathogens.

\section{MATERIALS AND METHODS}

The fresh mature leaves were collected from campus garden, Vellore Institute of Technology, Vellore, Tamil Nadu, India. The chemicals, including $\mathrm{AgNO}_{3}$, potato dextrose agar, mueller-hinton agar, ferric chloride $(0.1 \%)$, phosphate buffer $(0.2 \mathrm{M}, \mathrm{pH} 6.6)$, trichloroacetic acid $(10 \%)$, ascorbic acid $(1 \%)$ and potassium ferricyanide $(1 \% \mathrm{w} / \mathrm{v})$ were purchased from Hi-media Laboratories Pvt. Ltd, Mumbai, India. DPPH from Sigma-Aldrich and the fungal cultures Aspergillus niger, Aspergillus flavus, Aspergillus fumigates were collected from Vellore Institute of Technology, School of Bio Sciences and Technology (SBST).

\section{Preparation of plant extract}

The leaves were washed individually under the running water and then with Milli-Q (double distilled) water, it was then air dried and 10 $\mathrm{g}$ of the dried leaves were measured and made into a paste by mortar and pestle in $100 \mathrm{ml}$ of distilled water. The liquid was further boiled at a high temperature of $600^{\circ} \mathrm{C}$ for $2 \mathrm{~min}$ by using the heating mantle. The extract was passed through Whatman filter paper twice, and the extract was stored at $2-4^{\circ} \mathrm{C}$ in the refrigerator for further use.

\section{Synthesis of silver nanoparticles}

The synthesis of silver nanoparticles was performed in Erlenmeyer flask that consisted of $90 \mathrm{ml}$ of silver nitrate solution $(1 \mathrm{mmol}$ of $\mathrm{AgNO}_{3}$ in $90 \mathrm{ml}$ of double distilled water). The solution was prepared on room temperature at $37^{\circ} \mathrm{C}$ under static condition.

\section{Characterization of silver nanoparticles}

The 90-ml silver nitrate solution was added to $10 \mathrm{ml}$ of leaf extract and was put in the shaker until a visible color change was observed. The 
readings were recorded at regular intervals of time and the absorbance was scanned using the UV-Vis spectra, at a wavelength of 350-500 $\mathrm{nm}$. Further, the mixture was double centrifuged for pellet collection at 10,000 rpm for $5 \mathrm{~min}$; the pellet was collected in vials and stored for cryopreservation at- $4^{\circ} \mathrm{C}$. The vials were taped and lyophilized for $6 \mathrm{~h}$. The powdered nanoparticles obtained were stored in plastic airtight containers in the refrigerator for further use.

\section{Non-enzymatic antioxidant assay}

\section{DPPH analysis}

The DPPH assay is preferred as a simple and rapid method for investigating the total antioxidant scavenging activity. The method was developed by Blois, the compound DPPH is a dark colored soluble powder of steady free-radical molecules, which is miscible either in methanol or ethanol solution. It contains an unpaired electron which gives its characteristic wavelength at $515 \mathrm{~nm}$ absorbance and when it gets paired off when it meets the antioxidant compound (like hydrogen donor), the strength of the absorption gradually decreases with a color change from purple to pale color. This change of color is used as an indication for determination of total antioxidant compounds from the absorbance measured [13].

In this method, $4.3 \mathrm{mg}$ of DPPH compound was dissolved in a methanol solution of $3.3 \mathrm{ml}$, which was covered in aluminium foil to protect from the light. For the control, $150 \mu \mathrm{l}$ of the prepared DPPH solution was taken and absorbance was measured at $517 \mathrm{~nm}$. For the sample reading, (10-30 $\mathrm{mg}$ ) of bio-reduced silver nanoparticles were dissolved in $150 \mu \mathrm{l}$ of methanol solution and the standard ascorbic acid (10-30 mg) was also uniformly dissolved in $150 \mu \mathrm{l}$ of methanol solution. The sample was further diluted with methanol up to $3 \mathrm{ml}$ and $150 \mu \mathrm{l}$ of DPPH solution. Now, absorbance was checked after $15 \mathrm{~min}$ at an absorbance of $517 \mathrm{~nm}$, setting methanol as a blank solution. The DPPH scavenging activity was calculated using the formula:

$$
\% \text { of Scavenging }=\frac{\text { Absorbance of control-Absorbance of sample }}{\text { Absorbance of control }} \times 100
$$

The $\mathrm{IC}_{50}$ value is calculated by linear regression analysis by plotting between $\%$ inhibition and different concentrations of the sample or standard [14].

\section{Reducing power}

The substance having the capability of reduction, when it reacts with potassium ferricyanide $\left(\mathrm{Fe}_{3+}\right)$ and gives potassium ferrocyanide $\left(\mathrm{Fe}_{2+}\right)$, followed by reaction with ferric chloride and forms a ferrous complex with an absorbance maximum at $700 \mathrm{~nm}$.

Potassiam ferricyanide + Ferric chloride $\stackrel{\text { Ansioxtdant }}{\longrightarrow}$ Potassium forrocyanide + ferrous chloride

The different concentrations $(1-7 \mathrm{mg} / \mathrm{ml})$ of the test samples were dissolved in phosphate buffer $(2.5 \mathrm{ml})$ and potassium ferricyanide of $2.5 \mathrm{ml}$. The reaction mixture was then kept at $50{ }^{\circ} \mathrm{C}$ in a water bath for a period of $20 \mathrm{~min}$. When it was cooled down, $2.5 \mathrm{ml}$ of $10 \%$ of trichloroacetic acid was added and centrifuged at $5000 \mathrm{rpm}$ for 10 $\min$. The upper layer of the produced solution $(2.5 \mathrm{ml})$ was diluted with Milli-Q water $(2.5 \mathrm{ml})$ and ferric chloride solution of $0.5 \mathrm{ml}$ was added. The absorbance was recorded at $700 \mathrm{~nm}$. The control (ascorbic acid) with concentrations $(1-7 \mathrm{mg} / \mathrm{ml})$ was also prepared in the same way, without the addition of samples. The rise in absorbance indicates the reducing power of the different concentrations [15].

\section{Antifungal activity}

The disc diffusion assay was used to perform the fungicidal effect of the produced silver nanoparticles on plates containing Rose Bengal agar against the fungal strains Aspergillus niger, Aspergillus flavus, and Aspergillus fumigates. A loop full of the fungal strains was grown in the RBA medium and was allowed to incubate in dark conditions at room temperature. After $48 \mathrm{~h}$ of incubation, $10 \mathrm{ml}$ sterile distilled water was mixed with a loop full of the test spore and was swabbed on the plates containing the mueller hinton agar medium. The silver nanoparticles of different concentrations ( $25 \mu \mathrm{l}, 50 \mu \mathrm{l}$ and $75 \mu \mathrm{l}$ ) were loaded on sterile blank $6 \mathrm{~mm}$ Whatman filter paper discs and were placed on the surface of the medium. A positive control of ketoconazole disks and negative control of water was also added to the plate. The zone of inhibition was measured after incubation at room temperature for 24-48 $\mathrm{h}$ [16]. The relative percentage inhibition of the test fungal strains against positive control was calculated with respect to the given formula [17].

$$
100 \times \frac{(x-y)}{(z-y)}
$$

Where,

$\mathbf{x}$ : total area of inhibition of the test extract

y: total area of inhibition of the solvent

z: total area of inhibition of the standard drug

The total area of the inhibition was calculated by using area $=\pi r^{2}$; where, $r=$ radius of zone of inhibition

\section{RESULTS}

\section{Visual analysis}

The toxic silver nitrate reduction to non-toxic silver nanoparticles using the plant extract was observed. The silver nanoparticles gave a characteristic band of absorbance under the UV region, due to excitation mode of surface plasmon resonance (SPR), they undergo either to blue shift or red shift depending upon the size effects of nanoparticles. The fig. 1 shows the visual identification of color change from pale yellow to brown when the plant extract was added with silver nitrate solution. The color changes prove the synthesis of silver nanoparticles. The UV-Visible spectrophotometer was used to record the absorbance for wavelength in the range of 350 to $500 \mathrm{~nm}$. Fig. 2 demonstrates the maximum peak observed in $440 \mathrm{~nm}$ wavelength. Also, seen in Annona squamosal leaf extract, the absorbance peak for the visible color change was seen at 444 $\mathrm{nm}$ when silver nitrate solution was added to the leaf extract [18]. The characteristic absorbance peak by Krishnaraj et al. [19] for $A$. indica was at a wavelength of $420 \mathrm{~nm}$ for silver nanoparticles. The synthesis of nanoparticles was recorded until $37 \mathrm{~h}$, after which there was a slight decrease in the peak due to aggregation, but the peak was at a maximum when it reached the time of $3 \mathrm{~h}$. The pellet was collected after centrifugation at 10,000 rpm for $5 \mathrm{~min}$, freeze-dried in a lyophilizer and was sent for further characterization to confirm the synthesis of silver nanoparticles.

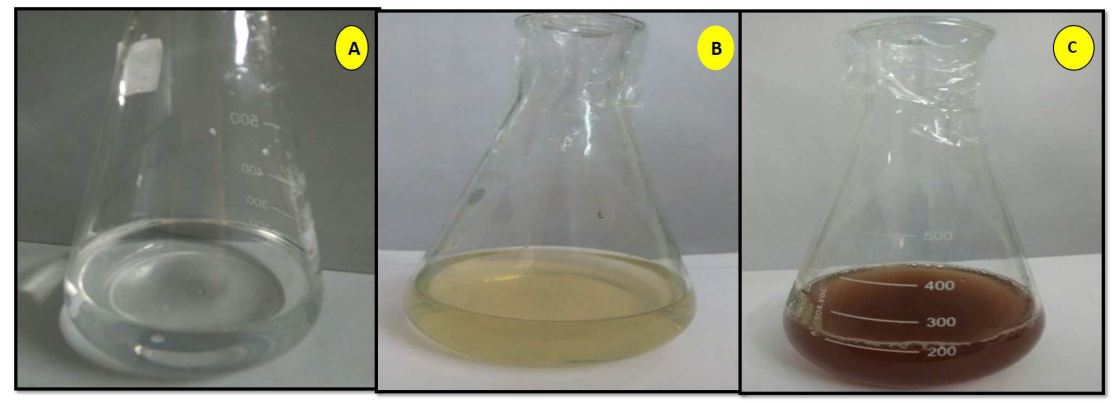

Fig. 1: Visual identification of silver nanoparticles A) $1 \mathrm{mmol}$ silver nitrate in $90 \mathrm{ml}$ of Mili-Q Water B) silver nitrate solution added with plant extract C) brown color change 


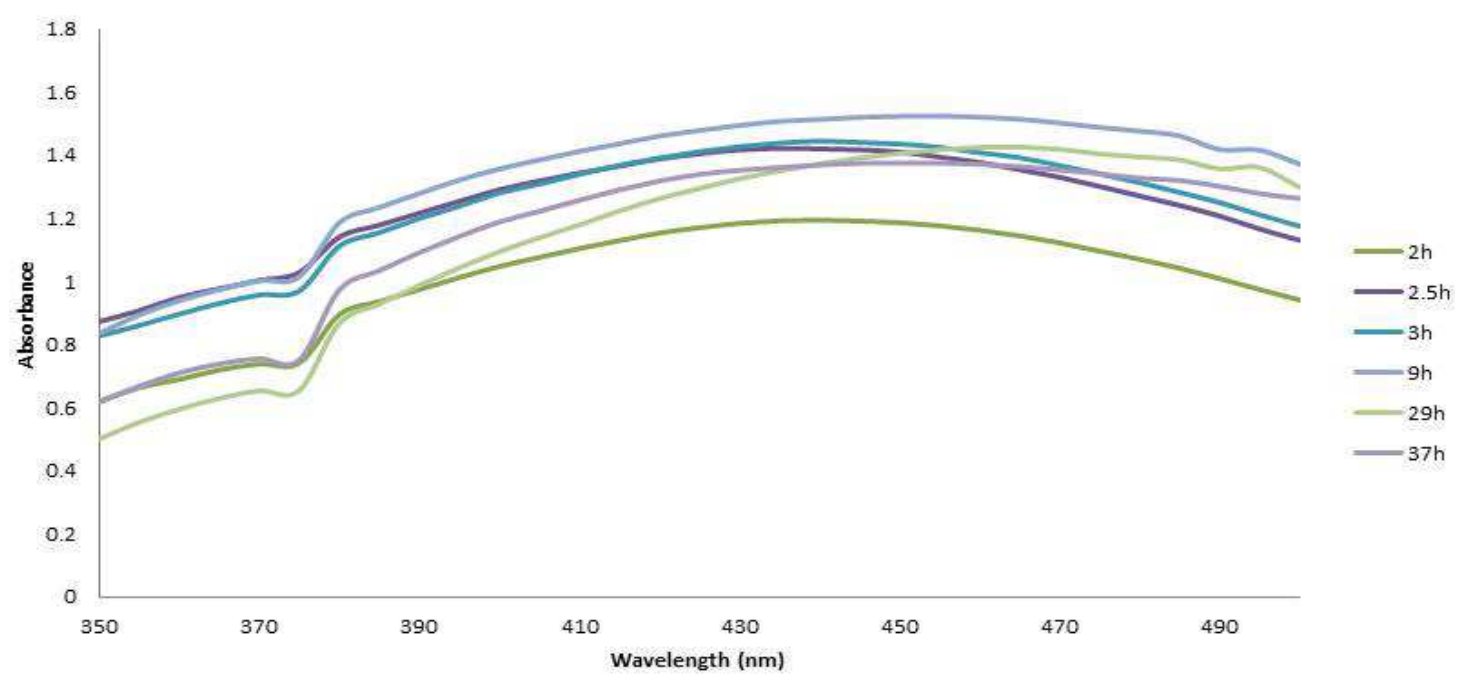

Fig. 2: The UV-visible readings absorbance of silver nanoparticles

\section{Fourier transform infrared spectroscopy (FTIR) analysis}

The fig. 3a demonstrates the possible functional groups involved in the reduction of silver ions, absorbance peak observed at 3263.56 $\mathrm{cm}^{-1}$ are predicted for alkynes, alcohols and phenols, $2320.23 \mathrm{~cm}^{-1}$ as nitriles group, $1631.78 \mathrm{~cm}^{-1}$ as aldehydes, ketones ( $\mathrm{C}=0$ stretch), alkenes, primary amines ( $\mathrm{N}-\mathrm{H}$ bend) and amides $(\mathrm{N}-\mathrm{H}$ bend and $\mathrm{C}=\mathrm{O}$ stretch), $1508.33 \mathrm{~cm}^{-1}$ as nitro groups ( $\mathrm{N}=0$ stretch), aminessecondary (N-H bend), $1022.27 \mathrm{~cm}^{-1}$ as alcohols, esters, carboxylic acid or ether ( $\mathrm{C}-\mathrm{O}$ stretch),amines and $501.49 \mathrm{~cm}^{-1}$ alkyl halides. And, the fig. $3 \mathrm{~b}$ shows the presence of functional groups due to phytochemicals of the leaf extract, the broad absorbance peak at $3290.56 \mathrm{~cm}^{-1}$ indicates the presence of alcohols, phenols and alkynes, $1635.64 \mathrm{~cm}^{-1}$ as amides $(\mathrm{N}-\mathrm{H}$ bend and $\mathrm{C}=0$ stretch) primary amines ( $\mathrm{N}-\mathrm{H}$ bend), aldehydes and ketones ( $\mathrm{C}=0$ stretch), alkenes, $1367.53 \mathrm{~cm}^{-1}$ as nitro groups $\left(\mathrm{N}=0\right.$ bend), and $1215.15 \mathrm{~cm}^{-1}$ as alcohols, esters, carboxylic acid or ether (C-O stretch) and 543.93 $\mathrm{cm}^{-1}$ as alkyl halides. The presence of organic compounds like flavonoids or terpenoids might be responsible for the synthesis of silver nanoparticles and the proteins in the leaf extract could be responsible for the stabilization of silver nanoparticles that is coated around it [20].

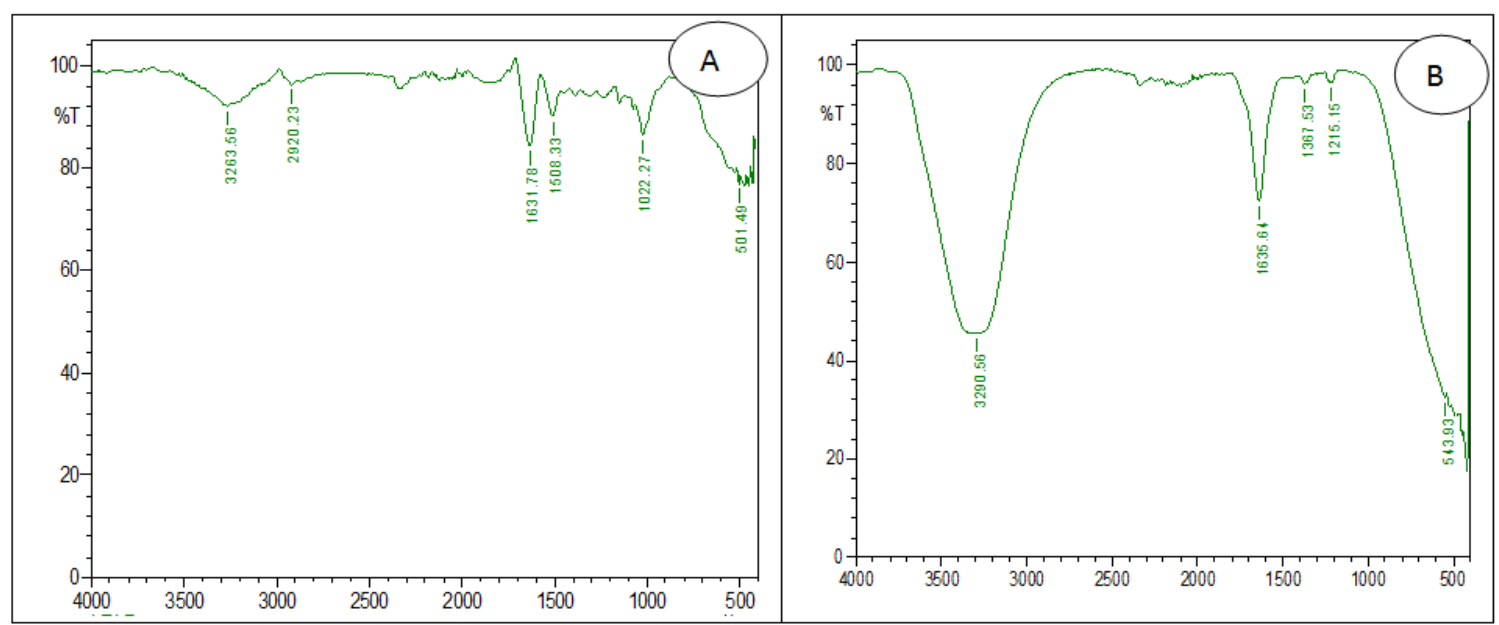

Fig. 3: Fourier transform infrared spectroscopy (FTIR) analysis results for A) silver nanoparticles B) the leaf extract

\section{Scanning electron microscope (SEM) analysis}

The morphology of the nanoparticles can be depicted by using the SEM, TEM analysis or the AFM analysis. The silver nanoparticles were found to be pseudo-spherical in shape, with size in the range of $20-50 \mathrm{~nm}$ as shown in the fig. 4. Most of the silver nanoparticles were uniformly distributed, but in the later time nearly $14 \mathrm{w}$, the particles formed an aggregation. The organic compounds or the reducing agents present in the extract may be responsible for the shape and size of the nanoparticles, where the compounds interlink with nanoparticles and reduce them [21].

\section{Transmission electron microscope (TEM) analysis}

The TEM results demonstrated in the fig. 5 Shows that the nanoparticles were poly-dispersive in nature, with varying shapes, but the majority were spherical in shape and the size of the nanoparticles was found to be in the range from 20 to $40 \mathrm{~nm}$. The size of the nanoparticles was further confirmed with the XRD analysis. The image also showed aggregations at some points, which may be due to phytochemicals present in the plant extract like polysaccharides, flavonoids, terpenoids, reducing sugars and amides, which are responsible in the biogenesis of silver nanoparticles [22]. 

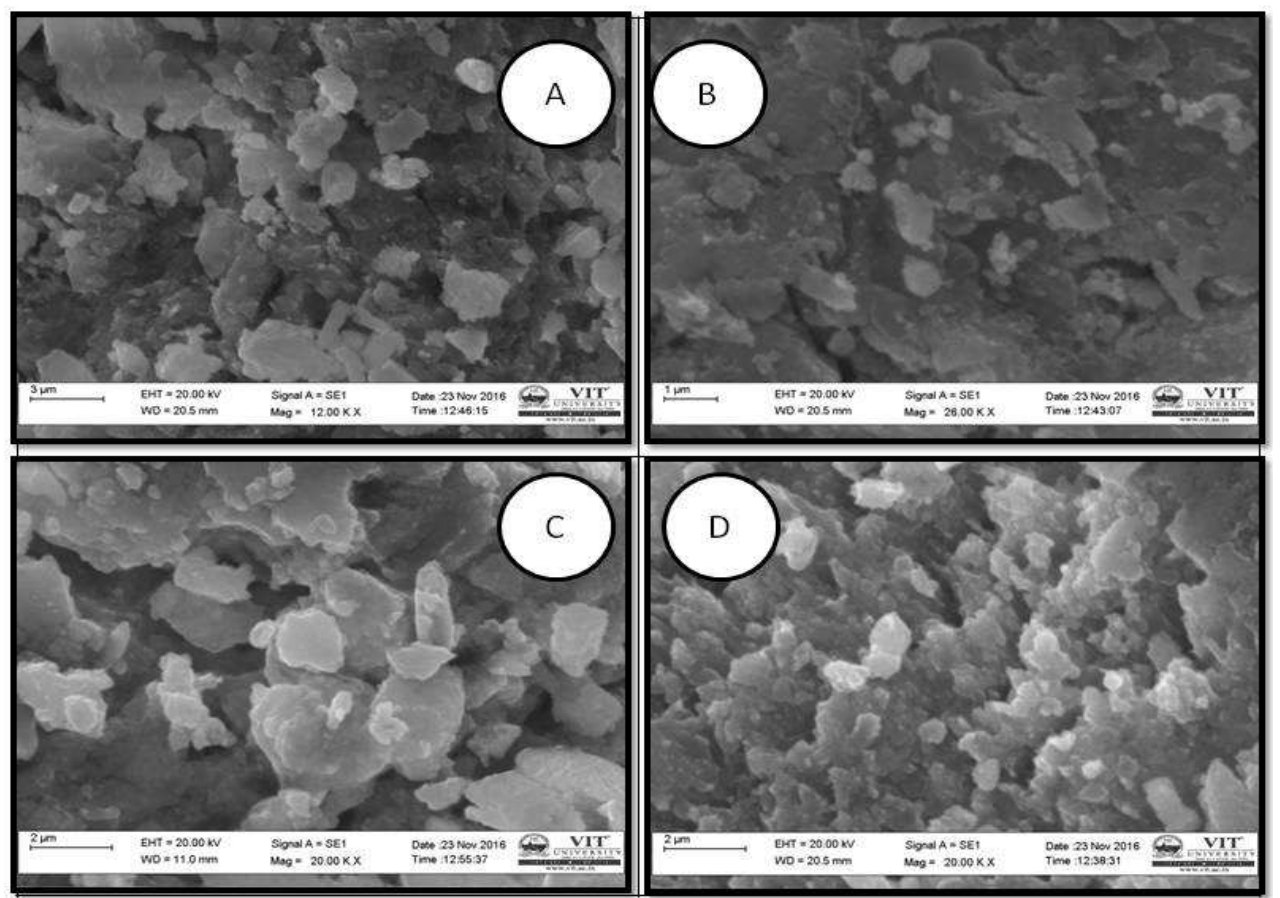

Fig. 4: SEM analysis of silver nanoparticles synthesized from Acalypha indica leaf extract

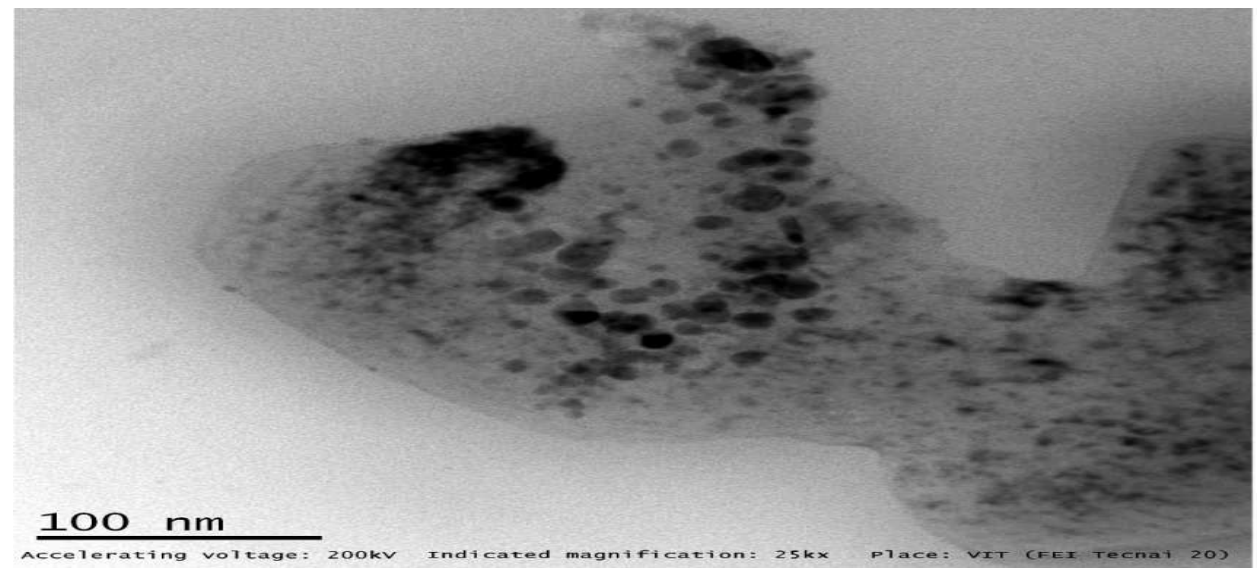

Fig. 5: TEM analysis of the silver nanoparticles

\section{Atomic force microscopy (AFM) analysis}

The atomic force microscopy analysis was utilized to check the surface roughness and morphology of the silver nanoparticles. The magnification is proportional to the intricacy of the particle size with that of the AFM tip and on the sample preparation[23]. The white patches in the fig. 6 depict the spherical nanoparticles which are shown in the micrograph and the 3D image shows the surface roughness due to the biomolecules or the organic compounds on the silver nanoparticles.

\section{X-ray diffraction (XRD) analysis}

The XRD is used in the determination of the size, shape, fraction analysis and parameter determination of the sample, the position of the peaks obtained from diffraction pattern also gives information about the translational size and shape of the crystal. The average size of the silver nanoparticles was calculated using the DebyeScherrer equation,

$$
\mathrm{D}=\frac{K \lambda}{\beta \cos \theta}
$$

Where,

$\mathrm{D}=$ is the thickness of the crystal,

$\mathrm{k}=$ constant, $\lambda=$ wavelength of the X ray's incident on the crystal,

$\beta=$ is the width at half maxima at (111) reflection at Bragg's angle $2 \theta$, while $\theta$ is the Bragg angle and the constant $(\mathrm{k})$ has a value of 0.94 and the wavelength $(\lambda)$ of $1.5406 \times 10^{-}[10]$.

The XRD pattern fig. 6 showed diffraction peaks at 28, 32, 38, 45, 55, 57, 69, 77 and 84 indexed as crystalline silver. The average size of the nanoparticles synthesized was $34.21 \mathrm{~nm}$, which was calculated from (table 1). The average size of the silver nanoparticles synthesized using Acalypha indica leaf extracts by Krishnaraj et al.[19] was nearly $35 \mathrm{~nm}$. The nanoparticles synthesized using $C$. citronella and $S$. verbascifolium were around 36 and $41 \mathrm{~nm}$ respectively presented by Joy Prabu and Johnson [21]. Apart from the assigned peaks for silver nanoparticles, peaks indexed at 55 and 57 shows additional peaks that may be due to the metalloproteinase or the bioorganic crystalline compounds, which might be present in the leaf extract. This observation also matched with Chistensen et al. [9]. 


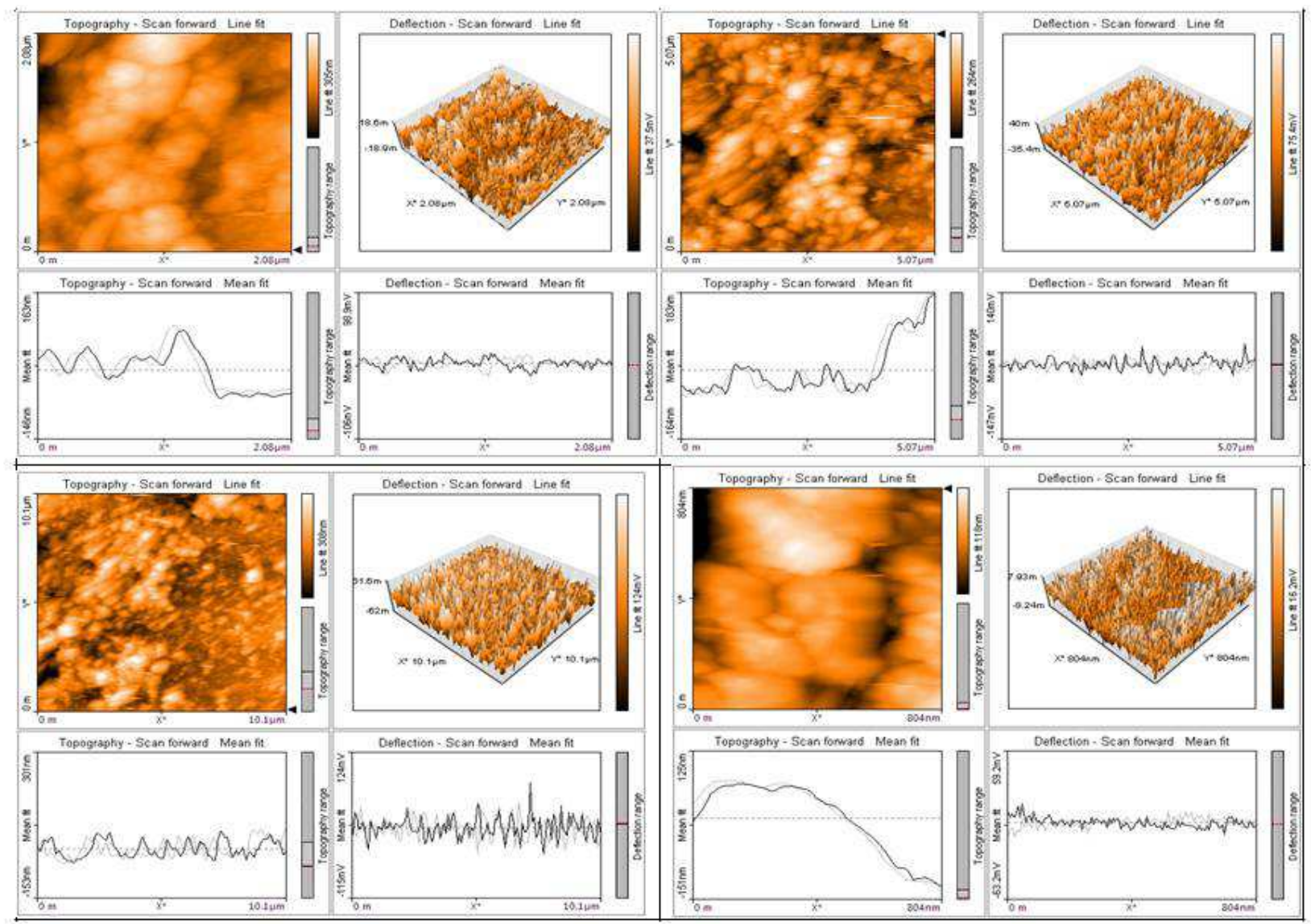

Fig. 6: Atomic force microscopy (AFM) of silver nanoparticles

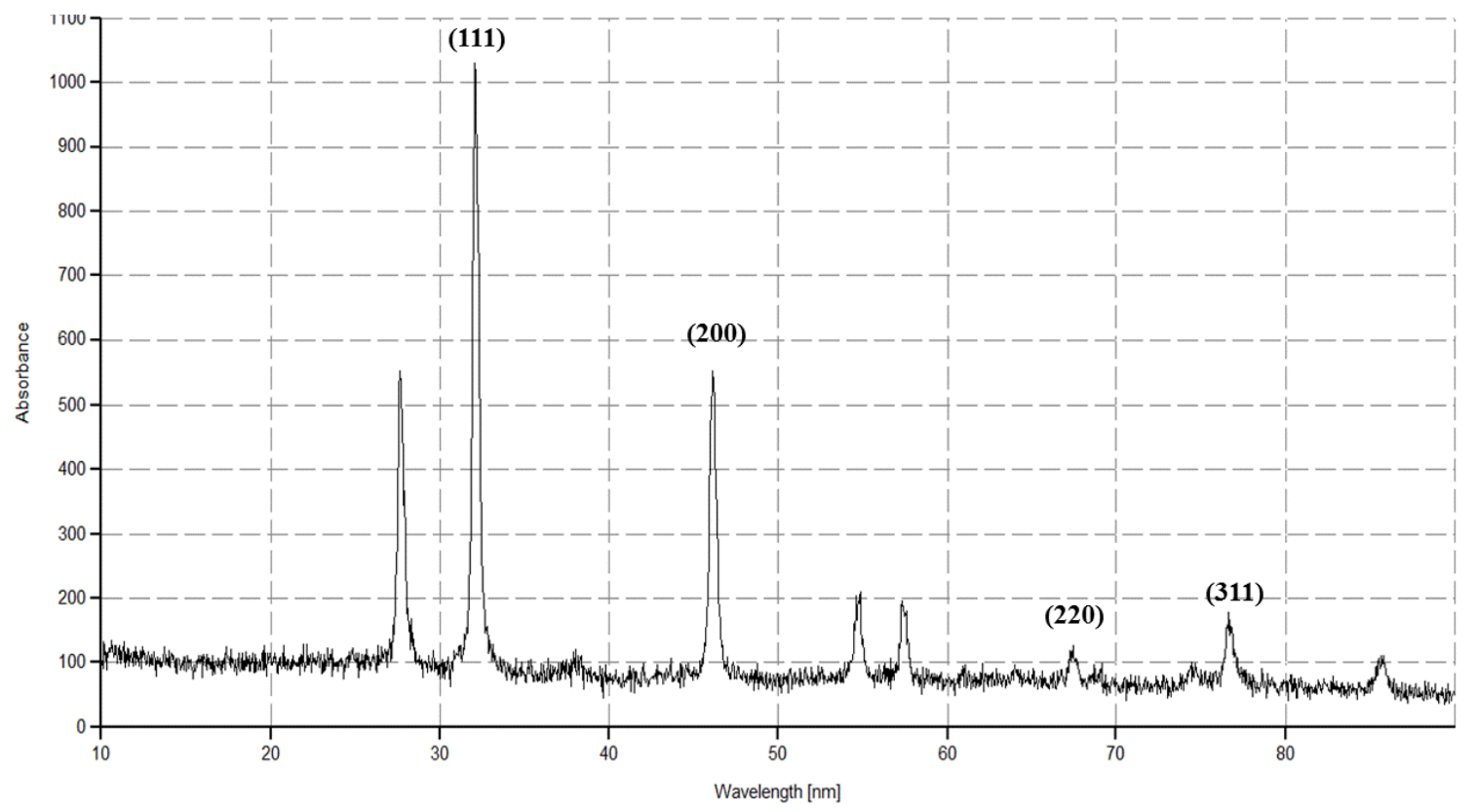

Fig. 7: XRD analysis of silver nanoparticles

\section{Energy dispersive spectroscopy (EDX) analysis}

The EDX gives an idea about the elemental analysis of the bio synthesized nanoparticles. The EDX profile shown in the fig. 8 Demonstrates a strong signal for the Ag atoms present, other peaks observed were $\mathrm{C}, \mathrm{O}$, and $\mathrm{Cl}$ biomolecules involved in the capping on the surface of these nanoparticles.

The $3 \mathrm{keV}$ is the typical absorption peak of the silver nanocrystal, the similar absorption peak is visible by Saware et al. [23]. 
Table 1: Average size analysis of silver nanoparticles from XRD analysis

\begin{tabular}{|c|c|c|c|c|}
\hline Position (nm) & Height (ABS*) & FWHM* (nm) & d-spacing $(\AA)$ & Particle size (nm) \\
\hline 28.075 & 510.8 & 0.625 & 0.317 & 22.87 \\
\hline 32.01 & 1002.56 & 0.452 & 0.278 & 31.19 \\
\hline 38.83 & 102.5 & 0.278 & 0.231 & 52.89 \\
\hline 46.51 & 506.8 & 0.289 & 0.195 & 52.23 \\
\hline 55.29 & 201.6 & 0.358 & 0.166 & 43.37 \\
\hline 57.62 & 198.62 & 0.332 & 0.159 & 47.67 \\
\hline 67.74 & 128.59 & 0.812 & 0.138 & 20.25 \\
\hline 77.68 & 187.26 & 0.968 & 0.122 & 18.39 \\
\hline 85.26 & 103.86 & 0.988 & 0.113 & 19.08 \\
\hline
\end{tabular}

The average particle size of silver nanoparticles is $34.21 \mathrm{~nm},{ }^{*}$ FWHM= Full width half maximum. ${ }^{*} \mathrm{ABS}=\mathrm{Absorbance}$

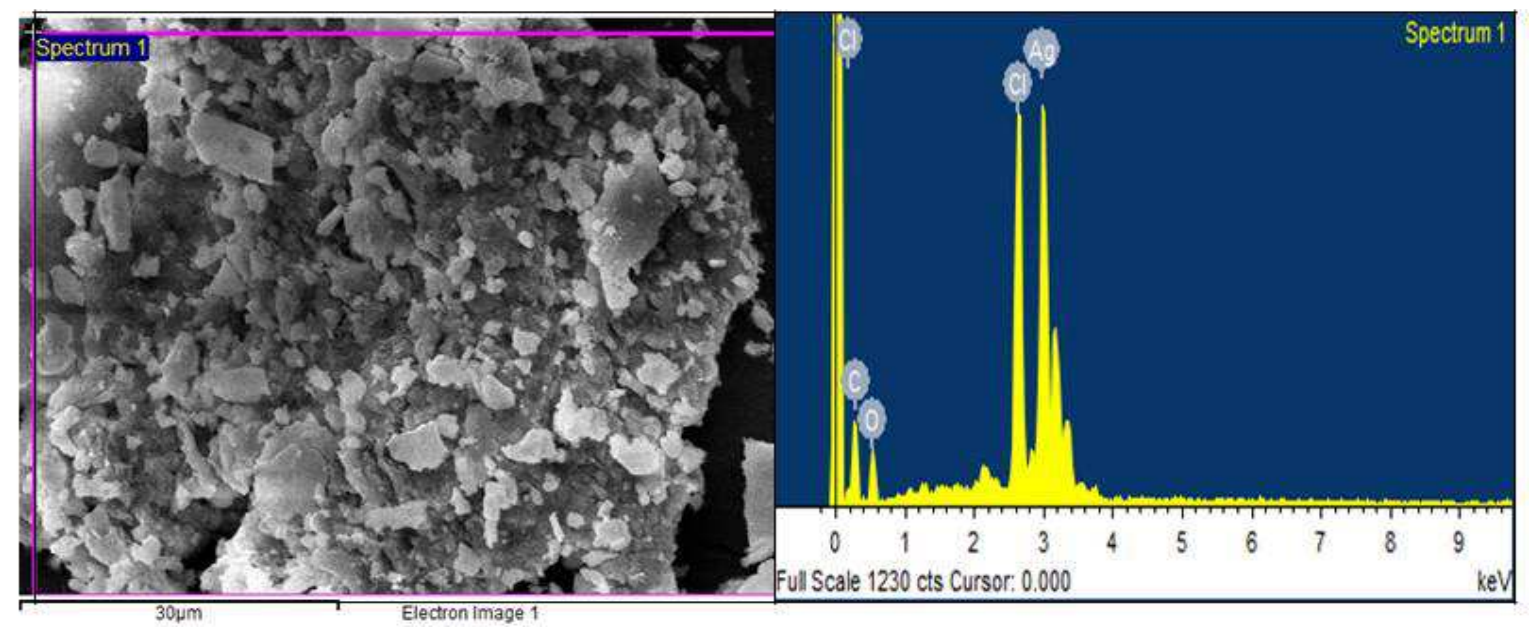

Fig. 8: EDX of silver nanoparticles

\section{Antioxidant activity}

A compound having one or more unpaired electrons in its outer shell is known as a free radical. These radicals are products of oxygen metabolism during the mitochondrial oxidative phosphorylation and are also unstable molecules, which can react with any molecule and become stable. reactive oxygen species (ROS) are the highly reactive molecule which has the capability of destroying the cellular components, and if these radicals are captured by the cellular components, it may lead to diseases like aging, osteoporosis, atherosclerosis, diabetes, different types of stroke, Neurodegenerative diseases like the Alzheimer's, Parkinson, cardiovascular disorders and can also spoil food or degrade materials like the rubber or lubricating oils [24].

\section{2,2-diphenyl-1-picrylhydrazyl (DPPH) assay}

The DPPH assay is the most acceptable, fastest and simplest method for the calculation of the free radical scavenging activity. As shown in the fig. 9 the Ag nanoparticles shows better antioxidant property than the standard ascorbic acid with an $\mathrm{IC}_{50}$ value at $5 \mathrm{mg} / \mathrm{ml}$, while standard showed values of 6-7 $\mathrm{mg} / \mathrm{ml}$.

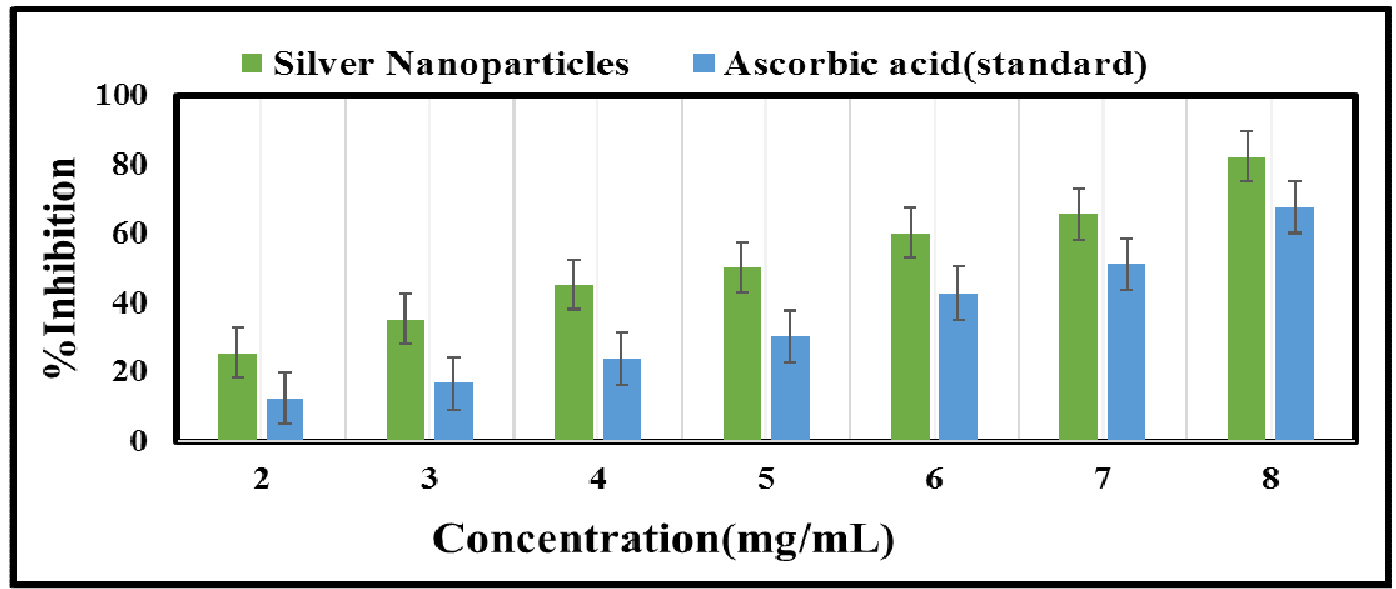

Fig. 9: DPPH scavenging activity of silver nanoparticles when compared with the standard ascorbic acid, measurements were done in triplicates $(n=3$, mean $\pm S D)$ 


\section{Reducing power}

The compounds that can reduce are the electron donors and can act as primary or secondary metabolites. In this method, the evaluation is done based on the color change from yellow to various shades of blue or green. The conversion of the ferricyanide complex to the ferrous form indicates the presence of the reducers. The color changes were observed at the absorption of $700 \mathrm{~nm}$. Moein et al. [25] had also performed a ferric reducing assay on Salvia herbs at an absorption of $700 \mathrm{~nm}$. As per the fig. 10 , the standard showed a lower reducing property than the synthesized silver nanoparticles.

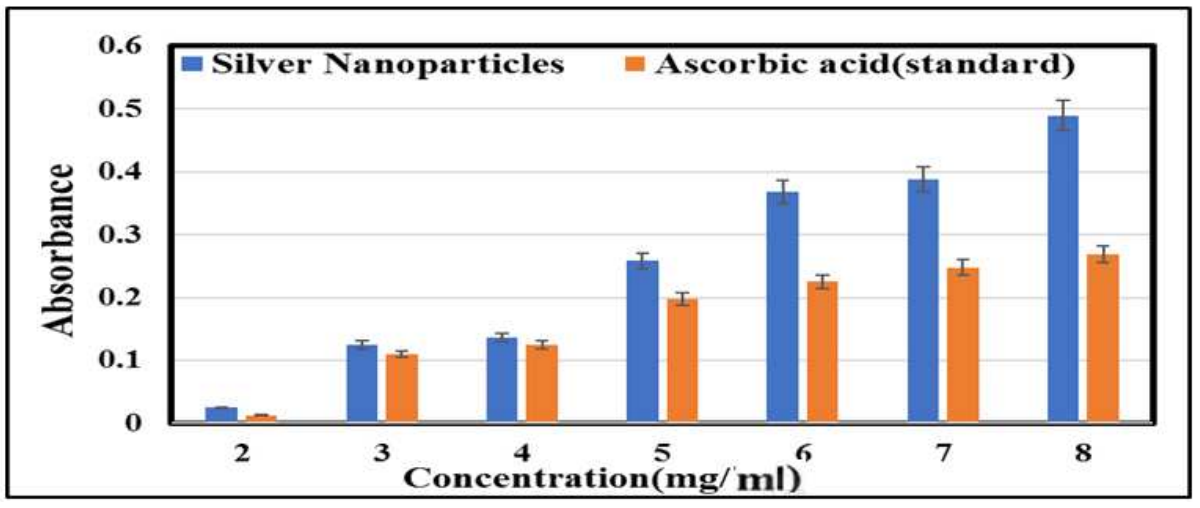

Fig. 10: The reducing power of silver nanoparticles when compared with standard ascorbic acid, measurements were done in triplicates $(n=3$, mean \pm SD $)$

Antifungal activity by disc diffusion method

In this method, the silver nanoparticles were subjected to antifungal activity against the common food pathogens like Aspergillus niger,
Aspergillus flavus and Aspergillus fumigates as shown in the fig. 11. The percentage inhibition was found to be maximum for Aspergillus fumigates with value of $133 \%$, and the maximum concentration for inhibition was at $75 \mu \mathrm{l}$ of silver nanoparticles as shown fig. 12 and fig. 13.

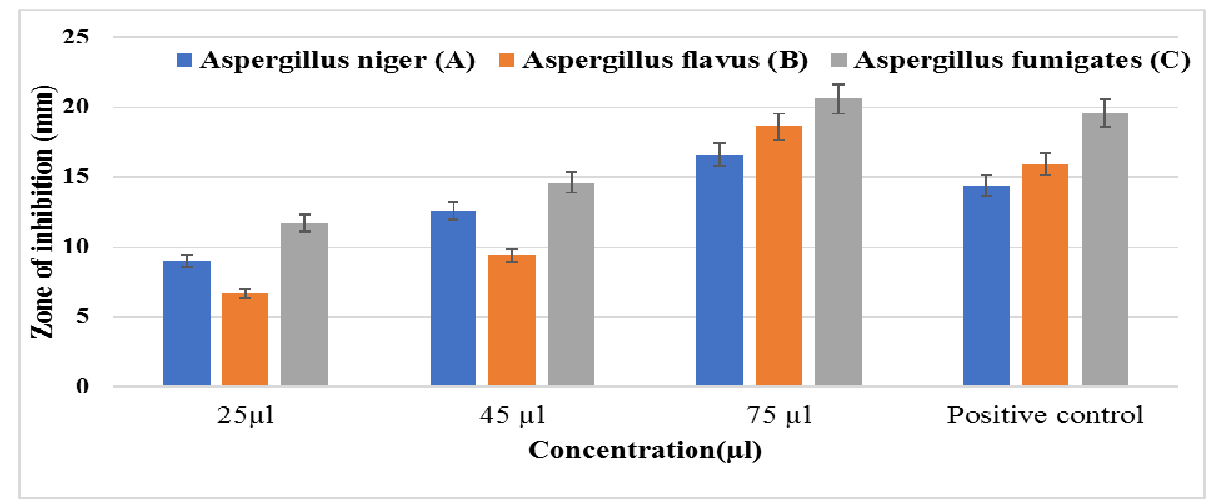

Fig. 11: Zone of inhibition of silver nanoparticles at different concentrations, measurements were done in triplicates ( $=3$, mean \pm SD)

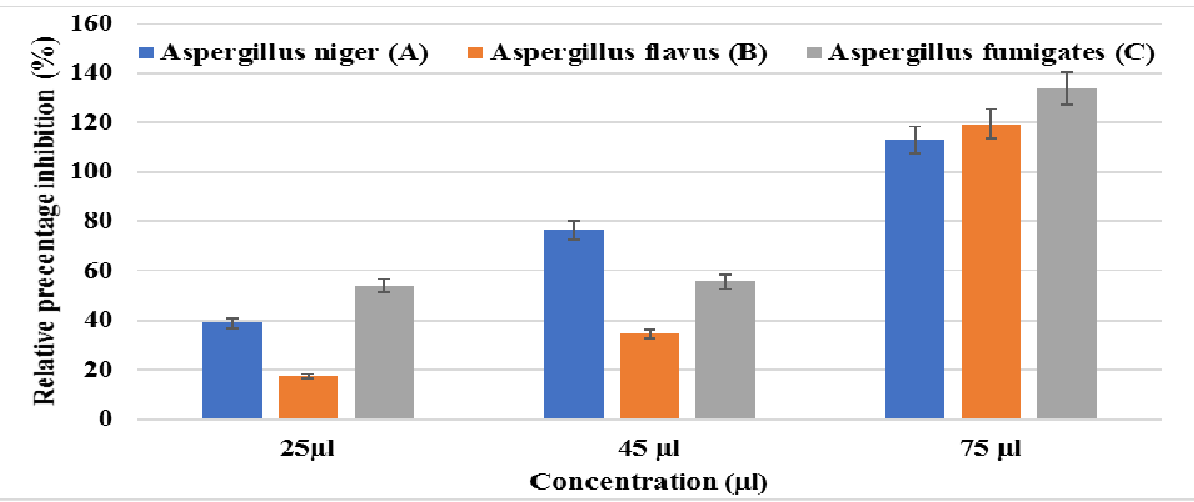

Fig. 12: The relative percentage inhibition (\%) of silver nanoparticles on different fungal strains, measurements were done in triplicates $(n=3$, mean \pm SD) 

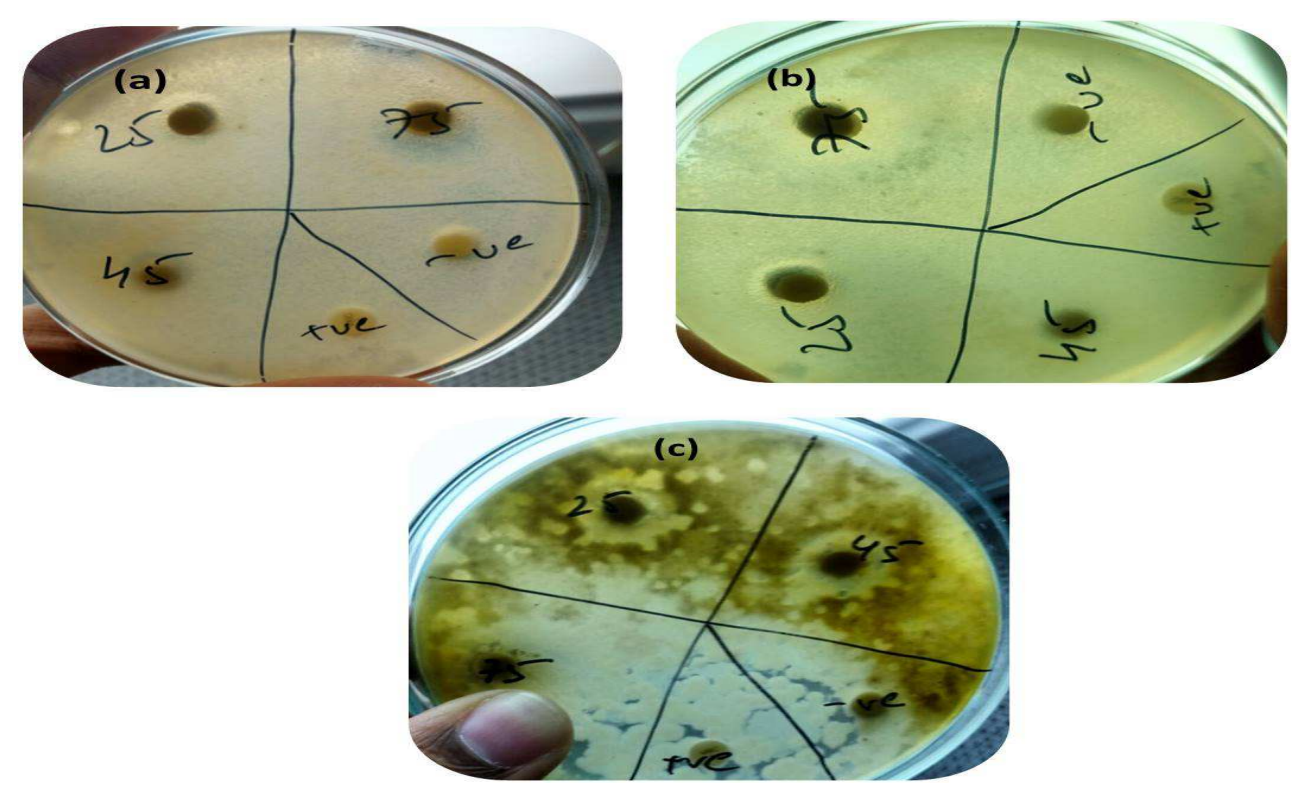

Fig. 13: Antifungal activity against foodborne pathogens

\section{DISCUSSION}

The leaves of $A$. indica contain acalyphine which are being used for the treatment as an antidiuretic agent, anti-inflammatory agent and for sore gum treatment. The recent discovery of the non-toxic phytochemicals, in the plants, which are acting as reducing agents, reduces the toxic chemical to non-toxic Ag nanoparticles that are being used for medicinal or technological applications these days [26]. The silver nanoparticles produced from the $A$. indica showed a brown color change at an optimized time of $3 \mathrm{~h}$. The maximum absorption was at $440 \mathrm{~nm}$ from the UV-visible analysis. Similar results were observed for silver nanoparticles performed by Asha et al. [27] and Rajeshkumar and Malarkodi [28] who got an absorbance peak in the range of 400 to $450 \mathrm{~nm}$ when synthesized from different sources. The XRD analysis proves the crystalline nature of the nanoparticles, similar results were also observed for Sivaramakrishnan et al. [29,30] and from the Debye-Scherrer equation, the average size of silver nanoparticles was found to be 34 $\mathrm{nm}$. The FTIR analysis gave information about the functional groups of the phytochemicals probably present in the plant extract involved in the reduction of the $\mathrm{Ag}$ nanoparticles. Then, the EDX analysis depicts the presence of $\mathrm{Ag}$ ions along with $\mathrm{Cl}, \mathrm{C}, \mathrm{O}$ etc., which are the functional groups adsorbed on the nanoparticles. The microscopic analysis by SEM and TEM gave an idea about the size and spherical shape of the nanoparticles. The antioxidant assay shows that silver nanoparticles can be used in therapeutic applications for the treatment of diseases caused by ROS free radicals. The antifungal activity of Aspergillus fumigatus was found to be the best when compared with other strains.

\section{CONCLUSION}

Scientists have shifted their interest from chemical or physical methods to biological methods as it does not involve a combination of abusive or toxic chemicals to human health or any involvement of immense machines or equipment. The biological methods incorporate other plant or microbial mediated methods that are cheap and easily accessible in daily life. The medicinal plant Acalypha indica has been used as a traditional medicinal plant due to its phytochemicals present in it. The various applications of the leaf extract have already been established till date. Now, in this study, the leaf extracts have been used for the biogenesis of the silver nanoparticles. The nanoparticles were characterized, confirmed by various microscopic and spectroscopic techniques. The produced silver ions were evaluated as a potential free radical scavenger when compared with the standard. The free radical causing diseases like atherosclerosis, cancer, inflammatory joint disease, asthma, diabetes, senile dementia and degenerative eye disease can be prevented with antioxidant property. Therefore, silver nanoparticles will be the best option for therapeutic or medical applications. The fungicidal activity was evaluated and the results concluded that it could be a good fungicidal agent, also it can prevent spoilage of costly fruits like avocado and prevent diseases which are caused in fruits or vegetables. This is the best low-cost, environment-friendly green synthesis of silver nanoparticles and can be performed in large-scale synthesis, and can be used in food industries like preservation or packaging of food.

\section{CONFLICT OF INTERESTS}

\section{Declared none}

\section{REFERENCES}

1. Krithiga N, Rajalakshmi A, Jayachitra A. Green synthesis of silver nanoparticles using leaf extracts of Clitoria ternatea and Solanum nigrum and study of its antibacterial effect against common nosocomial pathogens. Int J Nanosci 2015;8. http://dx.doi.org/10.1155/2015/928204

2. Rajeshkumar S, Malarkodi C, Vanaja M, Annadurai G. Anticancer and enhanced antimicrobial activity of biosynthesized silver nanoparticles against clinical pathogens. J Pharm Technol 2016;1116:165.

3. Gavhane A, Padmanabhan P, Kamble S, Jangle S. Synthesis of silver nanoparticles using extract of neem leaf and triphala and evaluation of their antimicrobial activities. Int J Pharma Bio Sci 2012;3:88.

4. Bobbu P, Netala VR, Aishwarya S, Reddy IRM, Kotakadi VS, Tartte V. Rapid synthesis of silver nanoparticles using aqueous leaf extract of Achyranthes aspera and study of their antimicrobial and free radical scavenging activities. Int J Pharm Pharm Sci 2016;8:341-6.

5. Begum NA, Mondal S, Basu S, Laskar RA, Mandal D. Biogenic synthesis of $\mathrm{Au}$ and ag nanoparticles using aqueous solutions of Black Tea leaf extracts. Colloids Surf B 2009;71:113.

6. Sujitha MV, Kannan S. Green synthesis of gold nanoparticles using citrus fruits (Citrus limon, Citrus reticulata and Citrus sinensis) aqueous extract and its characterization. Spectrochim Acta A Mol Biomol Spectrosc 2013;102:15.

7. Longhi JG, Perez E, Lima JJ, Candido LMB. In vitro evaluation of Mucuna pruriens (L.) Dc. Antioxidant activity. Braz J Pharm Sci 2011;47. http://dx.doi.org/10.1590/S198482502011000300011

8. Das RK, Gogoi N, Bora U. Green synthesis of gold nanoparticles using Nyctanthes arbortristis flower extract. Bioprocess Biosyst Eng 2011;34:615. 
9. Christensen L, Vivekanandhan S, Misra M, Mohanty AK. Biosynthesis of silver nanoparticles using Murraya koenigii (curry leaf): an investigation on the effect of broth concentration in reduction mechanism and particle size. Adv Mater Lett 2011;2:429.

10. Ali ZA, Yahya R, Sekaran SD, Puteh R. Green synthesis of silver nanoparticles using apple extract and its antibacterial properties. Adv Mater Sci Eng 2016;6. http://dx.doi.org/10.1155/2016/4102196

11. Rajaselvam J, Benila Smily JM, Meena R. A study of antimicrobial activity of Acalypha indica against selected microbial species. Int J Life Sci Pharma Res 2012;3:473-6.

12. Somchit MN, Abdul Rashid R, Abdullah A, Zuraini A, Zakaria ZA, Sulaiman MR, et al. In vitro antimicrobial activity of leaves of Acalypha indica linn (Euphorbiaceae). Afr J Microbiol Res 2010;4:2133.

13. Wollinger A, Perrin E, Chahboun J, Jeannot V, Touraud D, Kunz W. Antioxidant activity of hydro distillation water residues from Rosmarinus officinalis leaves determined by DPPH assays. C R Chim 2016;19:754.

14. Patel RM, Patel NJ. In vitro antioxidant activity of coumarin compounds by DPPH, super oxide and nitric oxide free radical scavenging methods. J Adv Pharm Technol Res 2011;1:52.

15. Jayanthi P, Lalitha P. Reducing the power of the solvent extracts of Eichhornia crassipes (mart.) solms. Int J Pharm 2011;3:126-8.

16. Rajeshkumar S, Malarkodi C, Paulkumar K, Vanaja M, Gnanajobitha G, Annadurai G. Algae mediated green fabrication of silver nanoparticles and examination of its antifungal activity against clinical pathogens. Int J Met 2014;1. http://dx.doi.org/10.1155/2014/692643

17. Kumar G, Karthik L, Rao KVB. Antibacterial activity of aqueous extract of Calotropis gigantea leaves, an in vitro study. Int J Pharm Sci Rev Res 2010;4:141.

18. Viveka R, Thangama R, Muthuchelian K, Gunasekaran P, Kaveri K, Kannana S. Green biosynthesis of silver nanoparticles from Annona squamosa leaf extract and its in vitro cytotoxic effect on MCF-7 cells. Process Biochem 2012;47:2405.

19. Krishnaraj C, Jagan EG, Rajasekar S, Selvakumar S, Kalaichelvan PT, Mohan N. Synthesis of silver nanoparticles using Acalypha indica leaf extracts and its antibacterial activity against water borne pathogens. Colloids Surf B 2010;76:50.

20. Bykkam S, Ahmadipour M, Narisngam S, Venkateswara, Kalagadda R, Chidurala SC. Extensive studies on X-ray diffraction of green synthesized silver nanoparticles. Adv Nanopart 2015;4:1-10.
21. Phatak RS, Hendre AS. Sunlight induced green synthesis of silver nanoparticles using sundried leaves extract of Kalanchoe pinnata and evaluation of its photocatalytic potential. Der Pharm Lett 2015;7:313.

22. Joy PH, Johnson I. Plant-mediated biosynthesis and characterization of silver nanoparticles by leaf extracts of Tragia involucrata, Cymbopogon citronella, Solanum verbascifolium and Tylophora ovata. Karbala Int J Mod Sci 2015;1:237.

23. Saware K, Sawle B, Salimath B, Jayanthi K, Venkataraman A. Biosynthesis and characterization of silver nanoparticles using Ficus Benghalensis leaf extract. Int J Res Eng Technol 2014;3:867.

24. Bhuiyan MAR, Hoque MZ, Hossain SJ. Free radical scavenging activities of Zizyphus mauritiana. World J Agric Sci 2009;5:318.

25. Moein MR, Moein S, Ahmadizadeh S. Radical scavenging and reducing power of Salvia mirzayanii subfractions. Molecules 2008; $13: 2804$.

26. Ahmad N, Sharma S, Alam MK, Singh VN, Shamsi SF, Mehta BR, et al. Rapid synthesis of silver nanoparticles using dried medicinal plant of basil. Colloids Surf B 2010;81:81.

27. Asha S, Asha A, Rajeshkumar S. Evaluation of phytochemical constituents and antimicrobial activity of silver nanoparticle synthesized Ipomoea nil against selected pathogens. Asian J Pharm Clin Res 2017;10:1-5.

28. Rajeshkumar S, Malarkodi C, Venkat KS. Synthesis and characterization of silver nanoparticles from marine brown seaweed and its antifungal efficiency against clinical fungal pathogens. Asian J Pharm Clin Res 2017;10:190-3.

29. Wilson A, Prabukumar S, Sathishkumar G, Sivaramakrishnan S. Aspergillus flavus mediated silver nanoparticles synthesis and evaluation of its antimicrobial activity against different human pathogens. Int J Appl Pharm 2016;8:43-6.

30. Murugesan S, Bhuvaneswari S, Sivamurugan V. Green synthesis, characterization of silver nanoparticles of a marine red alga Spyridia fusiformis and their antibacterial activity. Int J Pharm Pharm Sci 2017;9:192-7.

\section{How to cite this article}

- Soumya Menon, Happy Agarwal, S Rajeshkumar, S Venkat Kumar. Green synthesis of silver nanoparticles using medicinal plant Acalypha indica leaf extracts and its application as an antioxidant and antimicrobial agent against foodborne pathogens. Int J Appl Pharm 2017;9(5):42-50. 